\title{
Occurrence and Morphology of MB2 Canals in Maxillary First Molars in an Indian Subpopulation: A Cone Beam Computed Tomography Study
}

\author{
Aditya Shetty ${ }^{1}$ Raksha Bhat ${ }^{10}$ Bessy Babu ${ }^{1}$ Mithra N. Hegde ${ }^{1}$ Chitharanjan Shetty ${ }^{1}$ \\ Preethesh Shetty ${ }^{1}$ Priyanka Latha Senthilkumar ${ }^{1}$
}

\author{
${ }^{1}$ Department of Conservative Dentistry and Endodontics, AB Shetty \\ Memorial Institute of Dental Sciences, Nitte (Deemed to be \\ University), Mangalore, India \\ J Health Allied Sci ${ }^{\mathrm{NU}}$ 2022;12:101-105.
}

\author{
Address for correspondence Raksha Bhat, MDS, PhD, Department of \\ Conservative Dentistry and Endodontics, AB Shetty Memorial \\ Institute of Dental Sciences (ABSMIDS), Nitte (Deemed to be \\ University), Mangalore 575018, India \\ (e-mail: rkshabhat@gmail.com).
}

\begin{abstract}
Keywords

- CBCT

- MB2 canals

- root canal morphology

- 3D imaging

- maxillary molars

Introduction Molars have been known to display varied morphologies. Maxillary first molar is the tooth with the largest volume and most complex root and root canal anatomy; also, possibly the most treated and least understood posterior tooth. The present study aimed to investigate the occurrence and morphology of MB2 canals in maxillary first molars in an Indian subpopulation (Dakshina kannada) using cone beam $\mathrm{CT}(\mathrm{CBCT})$ imaging.

Materials and Methods A total of 330 maxillary molars were placed on "U-" shaped modelling wax template, mimicking the natural arch and digitally scanned, of which 196 scans met the inclusion criteria and were analyzed for unusual root canal anatomy by CBCT. To analyze the occurrence and morphology of the canals, the acquired data was examined by two endodontists and discussed till an agreement was reached.

Results The results were subjected to descriptive analysis. The majority of patients $103(52.6 \%)$ teeth showed the presence of MB2 canals. As much as $83.5 \%$ of teeth depicted Vertucci's type II morphology, and $16.5 \%$ teeth presented with Vertucci's type IV morphology.

Conclusion $\mathrm{CBCT}$ overcomes the limitations of conventional radiography. However, the decision to use $\mathrm{CBCT}$ in the management of endodontic problems must be based on a case-by-case basis and only when sufficient diagnostic information is not obtained from diagnostic tests.
\end{abstract}

\section{Introduction}

The successful outcome of nonsurgical root canal therapy is dependent upon location, thorough debridement, irrigation, and obturation of all canals and final restoration. ${ }^{1}$ It is widely agreed that a significant cause of root canal therapy failure is an inability to locate and manage all the canals of the root canal system. In canal anatomy, the extent and risk of missing aberrations are strictly related to the complexity of the root canal system. This is especially true when working on the complex anatomy of teeth like molars. ${ }^{2}$
DOI https://doi.org/ $10.1055 / \mathrm{s}-0041-1736268$. ISSN 2582-4287.

\footnotetext{
(c) 2021. Nitte (Deemed to be University). All rights reserved. This is an open access article published by Thieme under the terms of the Creative Commons Attribution-NonDerivative-NonCommercial-License, permitting copying and reproduction so long as the original work is given appropriate credit. Contents may not be used for commercial purposes, or adapted, remixed, transformed or built upon. (https://creativecommons.org/ licenses/by-nc-nd/4.0/) Thieme Medical and Scientific Publishers Pvt. Ltd., A-12, 2nd Floor, Sector 2, Noida-201301 UP, India
} 
The maxillary molar is the tooth with the largest volume and most complex root and root canal anatomy; also, possibly the most treated and least understood posterior tooth. The poorer prognosis was seen with the root canal treated maxillary first molars, in which the MB2 canals were missed. The MB2 canal orifice in maxillary molars is usually located either mesial to or in the pulpal groove connecting the main mesiobuccal canal and palatal canals, within $3.5 \mathrm{~mm}$ palatally and $2 \mathrm{~mm}$ mesially from the main mesiobuccal canal. ${ }^{3}$

Maxillary molars are teeth with multiple roots, along with different shapes and formations, which is why their internal canals are so complicated. One of the most commonly overlooked canals of maxillary molar teeth is the MB2 canal. This is because the first molars leave the chamber at a sharp mesial inclination in the MB2 channel in maxillary molars and then bent distally again, making it impossible for a clinician to detect and navigate the canal. ${ }^{4}$ It can be difficult to instrument the second mesiobuccal canal in the mesiobuccal root of the maxillary molars. Failure to treat the MB2 canals can lead to failure of root canal treatment in the future. $^{5}$

Cone beam CT (CBCT) is a modality of diagnostic imaging that offers high-quality, detailed three-dimensional (3D) representations of the maxillofacial skeleton's mineralized components. CBCT systems are available that provide lowdose, small field of view images with sufficient spatial resolution for endodontic diagnosis, therapeutic guidance, and posttreatment evaluation applications. ${ }^{6}$ Compared with conventional X-rays, CBCT shows a 3D view of the anatomical structures in different planes and produces in-depth description of the pulp space system without any superimposition of anatomical structures. ${ }^{6}$

According to a study done by Betancourt et al, the number of MB2 canals found in the maxillary first molars varies. The prevalence varies from $19.7 \%$ and $51.1 \%$ of in vivo studies, whereas it varies between $29 \%$ and $100 \%$ in vitro studies. ${ }^{6}$ An increased incidence of MB2 canals (90\%) in maxillary first molars were found by Verma and Love in the New Zealand population. $^{7}$ In the American population, Degerness and Bowles recorded an incidence of $79.8 \%$ of MB2 canals in the maxillary first molar. ${ }^{8}$ Somma et al found an incidence of $80 \%$ of MB2 canals in the Italian population, and Zheng et al found an incidence of $52.2 \%$ in the Chinese population. ${ }^{9,10}$ Studies on different ethnic populations have shown that there is a difference in the incidence of MB2 canals in maxillary first molars. In some populations, it shows a higher prevalence of 80 to $90 \%$, whereas in places, it shows a lesser prevalence of 40 to $50 \%$. This shows that the root canal anatomy varies in different populations. ${ }^{11}$

The present study aims at analyzing the occurrence and morphology of MB2 canal in maxillary first molars in an Indian subpopulation using CBCT imaging.

\section{Materials and Methods}

Based on previous studies, in south Indian population, an expected frequency of $15 \%(\mathrm{P})$, an acceptable margin of error $3 \%$ with $95 \%$ confidence interval, and a sample size of 330
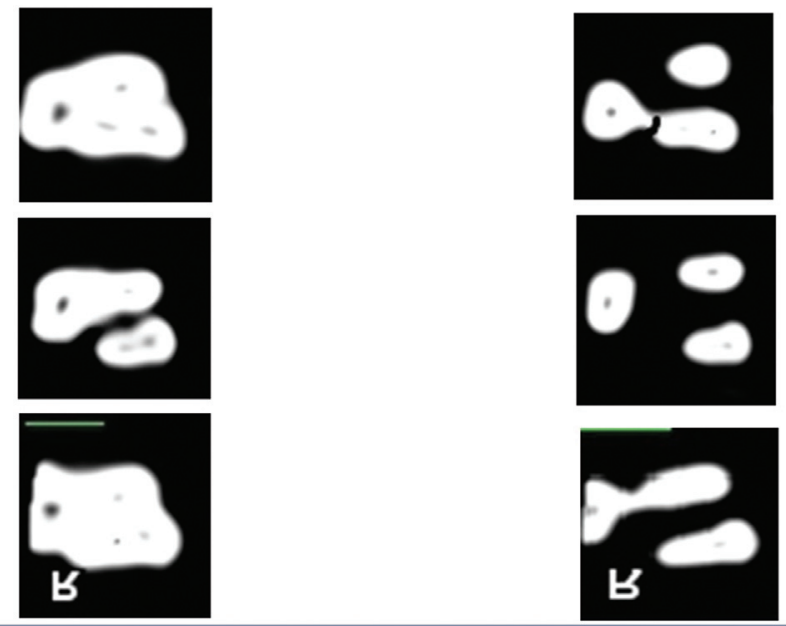

Fig. 1 Cross-sectional image (middle third).

was estimated for the present study using Epi Info StatCalc statistical software (7.2.0.1). Maxillary first molars were collected and disinfected following Occupational Safety and Health Administration (OSHA) regulations. Only maxillary first molars with three roots were included in the study. The teeth with resorbed, incomplete, and fractured roots were excluded from the study.

For analysis of unusual root canal anatomy by CBCT, "U-" shaped templates mimicking the natural arch were made using modeling wax. CBCT images were analyzed using PLANMECA Promax 3D MID system. The PLANMECA Romexis 4.3.0 $\mathrm{R}$ was used, according to the manufacturer's instructions. The image capturing parameters were set at $90 \mathrm{kV}$, with exposure time of 12 seconds at $8.0 \mathrm{~mA}$ current. The CBCT imaging was performed by a dental radiologist following the as low as reasonably practicable (ALARP) protocol. The data collected from CBCT was assessed with imaging software (-Figs. 1 and 2). The contrast and magnification of the device were regulated when required. All the images were analyzed by two operators, and the results were tabulated after a general agreement was agreed upon.

\section{Results}

The images obtained were analyzed for the occurrence and morphology of MB2 canals. In the presence of MB2 canals, Vertucci's classification was employed to classify the root canal configuration. Data interpretation was performed using imaging software and subjected to descriptive

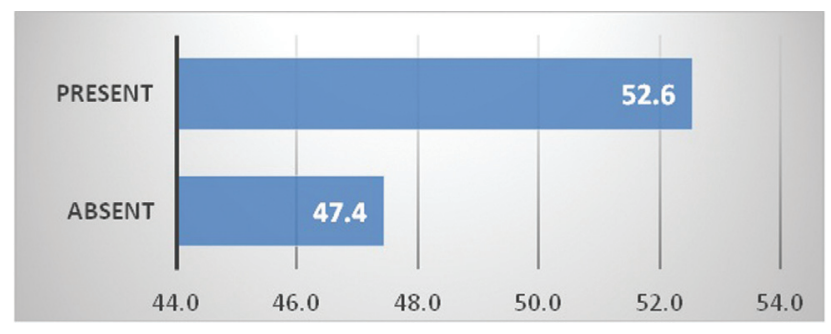

Fig. 2 Percentage of MB2 canals in maxillary first molars under cone beam $C T(C B C T)$. 


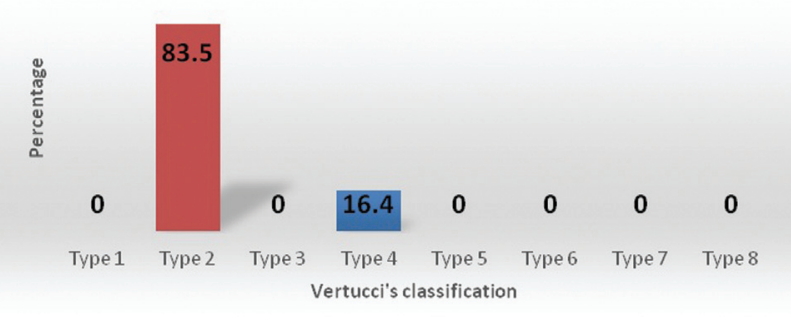

Fig. 3 Morphology of MB2 canal in maxillary first molars, according to Vertucci's classification.

statistical analysis using McNamara analysis. A total of 196 maxillary first molars were evaluated using CBCT in this study, of which 103 teeth showed the presence of MB2 canals (52.6\%) (-Fig. 2). Out of 103 teeth, 83.5\% teeth showed type II morphology, and 16.4\% (17 teeth) showed type IV morphology (-Fig. 3).

\section{Discussion}

The consistency and quantity of the information collected from radiographic examinations are very significant in root canal therapy, since it influences the diagnosis, preparation of treatment, and prognostic ability. There are several instances of clinical practice where traditional intraoral radiography alone does not provide adequate information on pathological conditions, structural shapes and configurations, and relationships with positions. Effective root canal procedure requires proper root canal system cleaning, shaping, and filling. Clinicians must have a detailed understanding of the anatomy of the root canal for this reason. In teeth subjected to root canal treatment, anatomical differences can be present. The occurrence of the MB2 canal in the mesiobuccal root of the maxillary first molar is still a matter of concern in endodontics, in keeping with this viewpoint. The lack of identification and treatment of the MB2 canal would lead to a decrease in prognosis. ${ }^{12}$

In previous studies, it has been shown that there is a variation in the prevalence of root canals in different teeth in different ethnic populations. A higher prevalence of MB2 canals (90\%) in maxillary first molars were found by Verma and Love in the New Zealand population. ${ }^{7}$ They reported a single canal in $15 \%$, two canals in $20 \%$, and three or more canals in $65 \%$ of the teeth observed. In the American population, Degerness and Bowles observed an incidence of $79.8 \%$ of MB2 canals in maxillary first molars. ${ }^{8} \mathrm{~A}$ higher prevalence (80\%) of MB2 canals were found in maxillary first molars in an Italian population by Somma et al. ${ }^{9}$ Zheng et al found an incidence of $52.2 \%$ additional canals in the mesiobuccal root of maxillary first molar in a Chinese population. ${ }^{10}$ Moreover, they showed a higher occurrence of extra mesiobuccal canals in the age group 20 to 30 years. In the Japanese and Korean populations, they showed a prevalence of $55.6 \%$ and $71.8 \%$, respectively. On the contrary, low prevalence of MB2 canal (22\%) was found in a Nigerian population by AbiodunSolanke et al. ${ }^{13}$
Most Indian groups are derived from a combination of two genetically divergent populations: Central Asian-related ancestral northern Indians, Middle Easterners, Caucasians, and Europeans; and nonsubcontinent-related ancestral south Indians. ${ }^{14}$ The present study shows a report on the occurrence of the second mesiobuccal canal in maxillary first molars in an Indian subpopulation using CBCT.

The morphology of the mesiobuccal root of maxillary molars has been documented as a complex root canal system with fins, isthmuses, transverse anastomoses, and even the presence of a third canal. A second canal in the mesiobuccal root in permanent maxillary molars is one of the common variations. ${ }^{3}$ In the present study, out of 196 teeth, 103 teeth showed the presence of MB2 canal with CBCT imaging. It has almost always been agreed that the maxillary first molar has three canals, with an MB2 canal seen by Cleghorn et al and Imura et al in 56.8 to $80.9 \%$ of the cases. ${ }^{15,16} \mathrm{~A}$ similar finding has been recorded in the present study. In vitro studies have shown more incidences of MB2 canals in the mesiobuccal root of the maxillary first molars when compared with in vivo clinical studies. A study done by Pomeranz and Fishelberg on 100 maxillary molars found 69\% of MB2 canals in vitro but only $31 \%$ could be found in vivo. The incidence of two canals in the mesiobuccal root was higher in laboratory studies (60.5\%), compared with clinical studies (54.7\%). ${ }^{17}$ CBCT imaging has shown to have better identification of the MB2 canal in a study done by Matherne et al. ${ }^{18}$ In the present in vitro study, CBCT positively identified the MB2 canal, demonstrating their superiority and reliability compared with other diagnostic methods for detecting the presence or absence of the MB2 canal.

Depending on the methodology employed, the frequency of MB2 canals detection varies. The techniques usually used are radiographs, various sectioning methods, different social groups, with or without magnification, different age groups, etc. Difficulties during clinical practice like poor visibility into the pulp chamber would risk perforation and could show a lower occurrence of a mesiobuccal second canal in contrast to an in vitro study. The dentin covering the MB2 canal orifice makes it even more difficult. These canals could have difficult curvature in the coronal portion, which makes it difficult for the clinician to negotiate the canal. These could be the reason for in vivo studies to have a predominantly lower occurrence of second mesiobuccal canals when compared with the in vitro studies. ${ }^{12}$

In the current report, 103 (52.6 percent) teeth displayed MB2 canal orifice when they were analyzed under CBCT, while in all 196 teeth analyzed for this study, palatal root only had single canal orifices. These findings were almost identical to those reported by Zheng et al, who reported a 52.2 percent incidence. ${ }^{10}$ Nevertheless, by comparison, under the CBCT assessment, Bauman et al reported a much higher MB2 canal incidence of up to 92 percent. ${ }^{19}$ These results vary from those of Al Shalabi et al who study showed an increased occurrence of $78 \%$ in maxillary first molars with four roots in an Irish population. ${ }^{20}$ The present study's reports were similar to those of Imura et al who showed a decreased occurrence of $47 \%{ }^{16}$ All the four canals of the 
maxillary first molars were in the mesiobuccal roots, which is similar to a study done by Sempire and Hartwell. ${ }^{21}$ The Irish population (80.4\%), Turkish population (93.5\%), Korean population (71.7\%), and Italian population (80\%) have shown a higher incidence; this variation could be because of differences in the techniques used, the sample sizes, and different geographical populations. Because of the difference in the CBCT resolution and the representative size of other studies, they could have shown a higher incidence when compared with our findings. Ex vivo research has shown an increased occurrence in the detection of additional root canals when compared with in vivo studies. Furthermore, studies using the clearing technique or sectioning using a dental operating microscope have shown higher detection rates than radiographic and CBCT examinations. ${ }^{22}$

In the present study, canal configurations were identified according to Vertucci's classification system (Graph 2), revealing the most prevalent type as Type II in $83.5 \%$. According to Rwenyonyi et al, type I was the most frequent, accounting up to 75.1 to $100 \%{ }^{23}$ However, Faramarzi et al found type II canal configuration as the most common in $71.3 \%{ }^{24}$

Several authors have discussed the factors leading to missing of second mesiobuccal canals in maxillary molars. Moreover, little has been discussed regarding the position of second mesiobuccal canals in the mesial root. The orifices of MB2 canal were usually seen on a line between the first mesiobuccal canal and the palatal canal. A study done by Peters et al showed that the space between the first mesiobuccal canal and the second mesiobuccal canal differs from $0.3 \mathrm{~mm}$ to $3.8 \mathrm{~mm} .{ }^{25}$ Kulild and Peters and Gilles and Reader showed that the mean distance from the first mesiobuccal canal to MB2 canal as $2.31 \mathrm{~mm}$ and $1.82 \mathrm{~mm}$, respectively. ${ }^{26,27}$ The closer the orifices are to each other, the better the likelihood of connecting the two canals inside the body of the root at any time. Most of the located pathways in this analysis fused into the apical section of the root canal and exited through one foramen. This is similar to the results of Kulild and Peters and Neaverth et al. ${ }^{26,28}$

However, the amount of radiation in CBCT is four times higher when compared with the conventional X-rays. According to the ALARP principle, the patient dose should be reduced as much as possible, and CBCT should be advised, considering the required diagnostic parameters. ${ }^{29,30}$

\section{Conclusion}

Proper mastery of the anatomy and morphology of the mesiobuccal root canal system is imperative for the proper pulp space therapy of the teeth. At first, the mesiobuccal pulp space of the upper first molars resembles the shape of the kidney. Eventually, because of secondary dentin deposition at the isthmuses, the poles become closer, leading to the formation of two canals. This makes it more tedious to detect the canals. This continued deposition of secondary dentin leads to constriction at the apex which, in turn, leads to single or multiple foramina. Hence, the age of the tooth could determine the variation in the anatomy of the mesiobuccal root morphology.
However, excessive radiation due to CBCT is not advisable for all the patients. We could use a dental operating microscope as an aid in detecting the presence of MB2 canal in maxillary first molars. The adjunctive use of the dental operating microscope could increase the ability of the dental clinician to locate MB2 canal in maxillary molars.

\section{Conflict of Interest \\ None declared.}

\section{References}

1 Borisova-Papancheva T, Panov V, Zaneva D. Frequency of location of a second mesiobuccal canal in maxillary first molars-review. Paper presented at: Varna Medical Forum, Bulgaria; 2017

2 Cantatore G, Berutti E, Castellucci A. Missed anatomy: frequency and clinical impact. Endod Topics 2006;15(01):3-1

3 Das S, Warhadpande MM, Redij SA, Jibhkate NG, Sabir H. Frequency of second mesiobuccal canal in permanent maxillary first molars using the operating microscope and selective dentin removal: a clinical study. Contemp Clin Dent 2015;6 (01):74-78

4 Hasan M, Raza Khan F. Determination of frequency of the second mesiobuccal canal in the permanent maxillary first molar teeth with magnification loupes ( $\times$ 3.5). Int J Biomed Sci 2014;10(03): 201-207

5 Chakradhar Raju RV, Sathe N, Morisetty PK, Veeramachaneni C. Endodontic management of a maxillary first molar with unusual location of second mesio buccal orifice. J Conserv Dent 2010;13 (03):162-164

6 Betancourt P, Navarro P, Cantín M, Fuentes R. Cone-beam computed tomography study of prevalence and location of MB2 canal in the mesiobuccal root of the maxillary second molar. Int J Clin Exp Med 2015;8(06):9128-9134

7 Verma P, Love RM. A Micro CT study of the mesiobuccal root canal morphology of the maxillary first molar tooth. Int Endod J 2011; 44(03):210-217

8 Degerness RA, Bowles WR. Dimension, anatomy and morphology of the mesiobuccal root canal system in maxillary molars. J Endod 2010;36(06):985-989

9 Somma F, Leoni D, Plotino G, Grande NM, Plasschaert A. Root canal morphology of the mesiobuccal root of maxillary first molars: a micro-computed tomographic analysis. Int Endod J 2009;42(02): 165-174

10 Zheng QH, Wang Y, Zhou XD, Wang Q Zheng GN, Huang DM. A cone-beam computed tomography study of maxillary first permanent molar root and canal morphology in a Chinese population. J Endod 2010;36(09):1480-1484

11 Peiris HR, Pitakotuwage TN, Takahashi M, Sasaki K, Kanazawa E. Root canal morphology of mandibular permanent molars at different ages. Int Endod J 2008;41(10):828-835

12 Coutinho-Filho TD, Gurgel-Filho ED, Souza-Filho FJ, Silva EJ. Preliminary investigation to achieve patency of MB2 canal in maxillary molars. Braz J Oral Sci 2012;11(03):373-376

13 Abiodun-Solanke IM, Dosumu OO, Shaba PO, Ajayi DM. Prevalence of additional canals in maxillary first molars in a Nigerian population. J Contemp Dent Pract 2008;9(07):81-88

14 Moorjani P, Thangaraj K, Patterson N, et al. Genetic evidence for recent population mixture in India. Am J Hum Genet 2013;93(03): 422-438

15 Cleghorn BM, Christie WH, Dong CC. The root and root canal morphology of the human mandibular first premolar: a literature review. J Endod 2007;33(05):509-516

16 Imura N, Hata GI, Toda T, Otani SM, Fagundes MI. Two canals in mesiobuccal roots of maxillary molars. Int Endod J 1998;31(06): $410-414$ 
17 Pomeranz HH, Fishelberg G. The secondary mesiobuccal canal of maxillary molars. J Am Dent Assoc 1974;88(01):119-124

18 Matherne RP, Angelopoulos C, Kulild JC, Tira D. Use of cone-beam computed tomography to identify root canal systems in vitro. J Endod 2008;34(01):87-89

19 Bauman R, Scarfe W, Clark S, Morelli J, Scheetz J, Farman A. Ex vivo detection of mesiobuccal canals in maxillary molars using CBCT at four different isotropic voxel dimensions. Int Endod J 2011;44 (08):752-758

20 al Shalabi RM, Omer OE, Glennon J, Jennings M, Claffey NM. Root canal anatomy of maxillary first and second permanent molars. Int Endod J 2000;33(05):405-414

21 Sempira HN, Hartwell GR. Frequency of second mesiobuccal canals in maxillary molars as determined by use of an operating microscope: a clinical study. J Endod 2000;26(11):673-674

22 Kalender A, Celikten B, Tufenkci P, et al. Cone beam computed tomography evaluation of maxillary molar root canal morphology in a Turkish Cypriot population. Biotechnol Biotechnol Equip 2016;30(01):145-150

23 Rwenyonyi CM, Kutesa AM, Muwazi LM, Buwembo W. Root and canal morphology of maxillary first and second permanent molar teeth in a Ugandan population. Int Endod J 2007;40 (09):679-683
24 Faramarzi F, Vossoghi M, Sokri A, Shams B, Khoshbin E. Cone Beam Computed Tomography study of root and canal morphology of maxillary first molar in an Iranian population. Avicenna J Dent Res 2015;7(01):e24038

25 Peters OA, Laib A, Göhring TN, Barbakow F. Changes in root canal geometry after preparation assessed by high-resolution computed tomography. J Endod 2001;27(01):1-6

26 Kulild JC, Peters DD. Incidence and configuration of canal systems in the mesiobuccal root of maxillary first and second molars. J Endod 1990;16(07):311-317

27 Gilles J, Reader A. An SEM investigation of the mesiolingual canal in human maxillary first and second molars. Oral Surg Oral Med Oral Pathol 1990;70(05):638-643

28 Neaverth EJ, Kotler LM, Kaltenbach RFClinical investigation. Clinical investigation (in vivo) of endodontically treated maxillary first molars. J Endod 1987;13(10):506-512

29 Shetty H, Sontakke S, Karjodkar F, Gupta P, Mandwe A, Banga KS. A Cone Beam Computed Tomography (CBCT) evaluation of MB2 canals in endodontically treated permanent maxillary molars. A retrospective study in Indian population. J Clin Exp Dent 2017;9 (01):e51-e55

30 Li G. Patient radiation dose and protection from cone-beam computed tomography. Imaging Sci Dent 2013;43(02):63-69 